\title{
Case Report \\ Sclerokeratoplasty as the Therapy for Corneal Perforation due to Exposure and Neurotrophic Keratopathy
}

\author{
Radoslaw Rozycki, Izabela Nowak-Gospodarowicz, Dominika Bialas, \\ Rafal Pawlik, and Marek Rekas \\ Ophthalmology Department, Military Institute of Medicine, 128 Szaserow Street, 04-141 Warsaw, Poland \\ Correspondence should be addressed to Radoslaw Rozycki; rrozycki@wim.mil.pl
}

Received 23 November 2013; Accepted 14 December 2013; Published 16 January 2014

Academic Editors: A. A. Bialasiewicz and V. Jhanji

Copyright (C) 2014 Radoslaw Rozycki et al. This is an open access article distributed under the Creative Commons Attribution License, which permits unrestricted use, distribution, and reproduction in any medium, provided the original work is properly cited.

A case report of exposure and neurotrophic keratopathy after acoustic neuroma surgery resulting in perforation if not managed appropriately and timely is presented. Sclerokeratoplasty on 360 degrees may be an effective treatment method of corneal perforation in complete anaesthetic cornea when the standard penetrating keratoplasty failed. At a 12-month follow-up, the patient is doing well. UCVA is 0.5 , the IOP is normal, and the graft remains clear. Systemic immunosuppression is the main disadvantage of this method. Further investigation is needed to assess the effectiveness and safety of this method.

\section{Introduction}

Acoustic neuromas (Vestibular Schwannomas) (VS) are oncologically benign tumours which constitute more than $90 \%$ of all cerebellopontine angle tumours and more than $10 \%$ of all primary brain tumours. Surgical excision of these tumours is one of the most challenging neurosurgical procedures because of their location close to vital structures such as the anterior inferior cerebellar artery (AICA) or the 7th and 8 th cranial nerves [1]. When the tumour exceeds $3 \mathrm{~cm}$, it might involve the trigeminal nerve causing a depressed corneal reflex, which is accompanied by peripheral facial nerve paresis leading to the development of exposure and neurotrophic keratopathy. This condition, especially with poor Bell's phenomenon, is usually resistant to conventional therapies and has a very unfavourable prognosis. Loss of the sensory innervation of the cornea decreased the number of corneal stem cells [2], decreased metabolic and mitotic rates in the corneal epithelium, and reduced acetylcholine and choline acetyltransferase concentrations $[3,4]$ resulting in the development of persistent epitheliopathy.

This chronic epithelial breakdown enables proteolytic enzymes to degrade the extracellular matrix components because they cannot protect corneal structural and signaling matrix proteins anymore. This condition may progress to corneal ulceration, perforation, and loss of the eye.
The ophthalmic goal of treatment is to protect the cornea from external irritating factors, to stop its progressive degradation, and to support its healing.

\section{Case Report}

The patient was a 64-year-old female with a 4-year history of exposure and neurotrophic keratopathy in the right eye due to unresolved peripheral facial nerve and trigeminal nerve palsies after acoustic neuroma surgery. The patient underwent bilateral cataract surgery at the age of 61 and, except for mild hypertension, remained healthy. After 2 years of satisfactory treatment of lagophthalmos with a gold eyelid weight, it was necessary to remove the weight from the right upper eyelid in order to perform an MRI scan. Despite the use of moisturizing drugs and eye taping, severe corneal ulcer developed 6 months after the removal of the weight. After 2 months of ineffective conservative treatment, the patient was referred to our clinic.

On admission, the corrected distance visual acuity (CDVA) was 0,01 (Snellen chart) and intraocular pressure (IOP) was $14 \mathrm{mmHg}$ in the right eye. CDVA was 1,0 in the left eye.

Peripheral right facial nerve palsy, lagophthalmos of 5 millimetres with paralytic ectropion, poor Bell's phenomenon, and complete corneal anaesthesia were noted in 


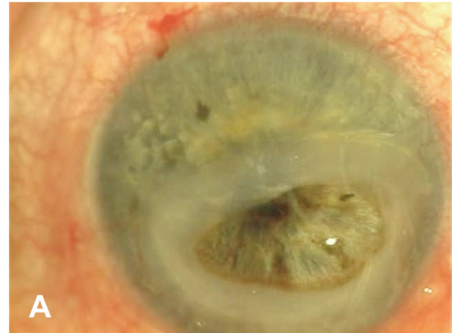

(a)

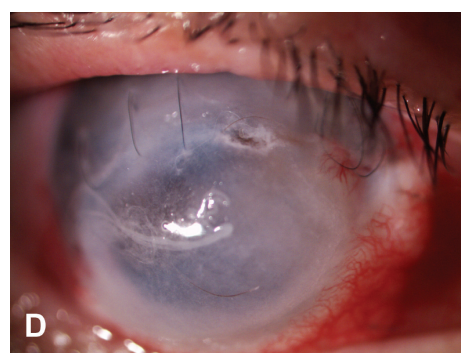

(d)

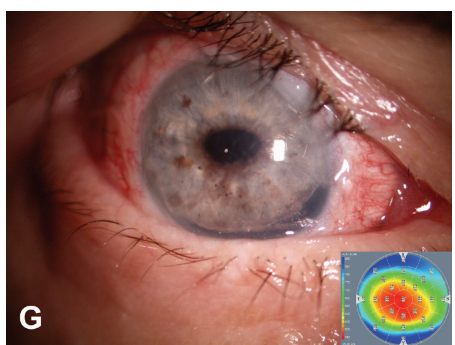

(g)

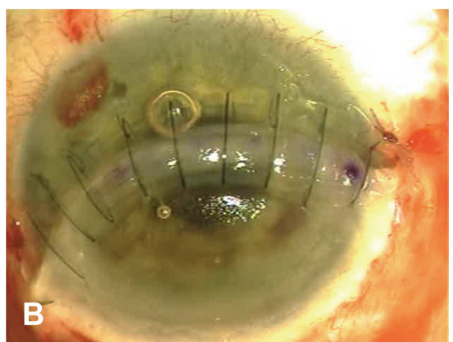

(b)

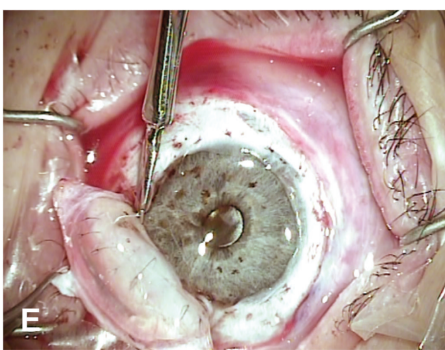

(e)

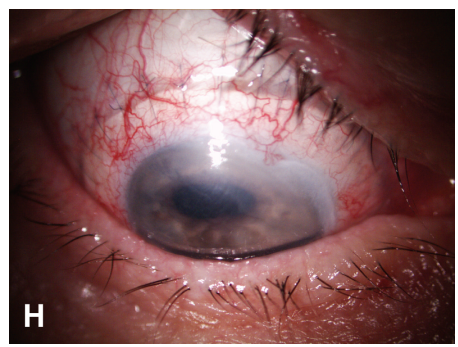

(h)

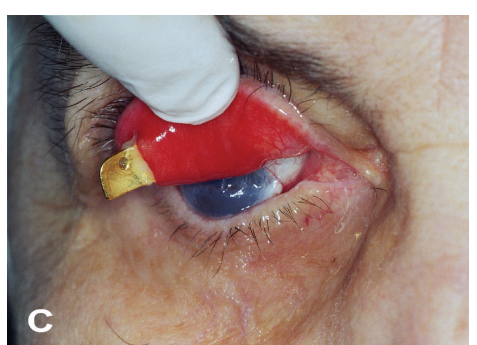

(c)

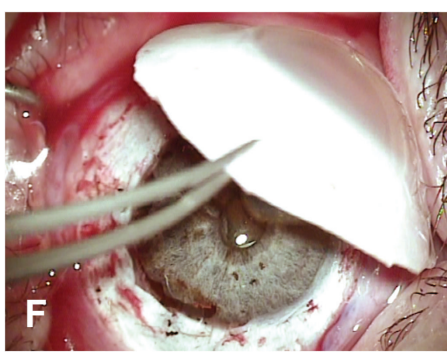

(f)

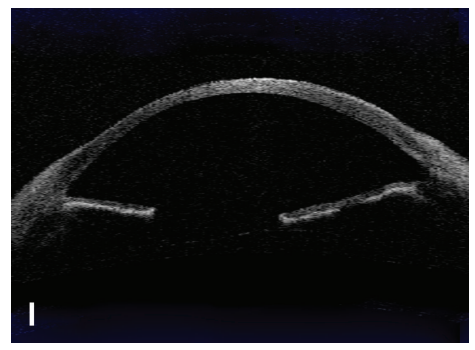

(i)

FIGURE 1: The anterior segment of the eye 12 months after sclerokeratoplasty on 360 degrees: pre- and postoperative picture and the surgical technique. (a) Corneal perforation (b) inferiorly decentred penetrating keratoplasty; (c) extrusion of the gold weight from the right upper eyelid; (d) graft rejection; (e) sclerokeratectomy (preparation of the cornea); (f) sclerokeratectomy (graft adaptation); (g) anterior segment of the eye and pachymetry map 12 months after surgery; (h) donor graft fitting 12 months after surgery; (i) anterior segment of the eye 12 months after the surgery (OCT-Visante).

the right eye. Slit lamp examination revealed ulceration with descemetocele in the lower part of the cornea in the right eye. The intraocular lens (IOL) was in place and other ocular structures and the left eye were without any pathological changes. Urgent amniotic membrane transplant (AMT) and complete tarsorrhaphy were performed in the right eye. The patient was discharged home on topical $0,5 \%$ levofloxacin and was followed-up in an outpatient clinic. 15 days after initial clinical improvement and partial removal of the tarsorrhaphy sutures the patient came to our emergency room with a corneal perforation in the right eye (Figure 1(a)). The patient noticed vision deterioration and admitted to having touched her cornea during the instillation of the eye drops. The patient was admitted to our clinic. Urgent inferiorly decentred penetrating keratoplasty was performed ([5], Figure 1(b)) due to the size of the perforation, its localisation, and vascularisation of the lower limbus. A new 1,8 $\mathrm{g}$ of gold weight (safe for MRI) was placed in the pretarsal space of the right eye and a correction of the paralytic ectropion was performed. Triple systemic immunosuppression (cyclosporine $\mathrm{A}$, mycophenolate mofetil, and prednisone) was administered. After 1 month, the gold weight was extruded from the scarred tissue of the right upper eyelid (Figure 1(c)). Despite eye taping, systemic immunosuppression, and visually normal upper limbus, no reepithelialization was noted. Graft rejection with scleral melt in the suture localisation occurred 3 months after the surgery (Figure 1(d)). Urgent sclerokeratoplasty on 360 degrees was performed in the right eye. Under general anesthesia, the recipient sclera was incised circumferentially $4 \mathrm{~mm}$ distally from the limbus and to $2 / 3$ of its thickness in depth. The anterior chamber was opened and filled with viscoelastic material. Anterior synechiae were lysed and the recipient cornea was removed with curved scissors $1 \mathrm{~mm}$ peripheral from the limbus. The adequate donor sclerocorneal graft was sutured to the recipient sclera with 10.0 nylon sutures. The anterior chamber was reformed with viscoelastic. Special care was taken to avoid injury of structures of the angle. The conjunctiva was reattached to the donor limbus ([6-9], Figures $1(\mathrm{e})$ and $1(\mathrm{f})$ ).

The immunosuppression scheme was introduced by the specialist in organ transplantations from our institute and included orally: cyclosporine A (CsA) $100 \mathrm{mg}$ bid varying to 
$50 \mathrm{mg}$ bid depending on drug concentration level in blood, mycophenolate mofetil (MMF) $1000 \mathrm{bid}$, and prednisone $40 \mathrm{mg}$ daily for 1 month and then tapered to $8 \mathrm{mg}$ per day until completion in POM12; locally: prednisolone acetate $1 \%$ $1 \mathrm{gtt}$ q2h daily limited to $1 \mathrm{gtt}$ qid from POM3.

At a 12-month follow-up, the patient is doing well (Figures $1(\mathrm{~g}), 1(\mathrm{~h})$, and $1(\mathrm{i})$ ). CDVA in the right eye is 0.5 (Snellen chart) and intraocular pressure (IOP) is $16 \mathrm{mmHg}$. The graft remains clear. No complications of the systemic immunosuppression have been noted. The patient receives regular followup in our clinic.

\section{Discussion}

This case shows how complicated the treatment of severe exposure and neurotrophic keratopathy after excision of the cerebellopontine angle tumour might be.

To our best knowledge, there are no standards for treatment of this condition.

Restoration of complete eyelid closure is crucial in order to prevent the cornea from mechanical injuries and enable proper impact of therapeutic agents.

Depending on the severity of impairment of the ocular surface, vitamins, collagenase inhibitors, anti-inflammatories and tear substitutes, cyclosporine, autologous serum, or grafts of the amniotic membrane may be used. Recent studies have also shown promising results on the use of nerve growth factor (NGF) [10-12], matrix proteins, and bioengineered matrix regenerating agent (RGTA) [13].

In this case, initial AMT with tarsorrhaphy brought about clinical improvement and therefore corneal perforation came as a surprise to us. The patient admitted that she might have touched the cornea during instillation of the eye drops. We believe that this is the direct cause of the perforation.

Classic treatment of corneal perforation involves the use of glue, the smallest patch grafts, and tectonic grafts $[14,15]$. After the first urgent decentred penetrating keratoplasty, the visual outcome was disappointing (the finger counting level). Despite systemic triple immunosuppression, there was no reepithelialization of the cornea and the graft was rejected. Moreover, apart from vascularization of the lower part of the corneal graft and limbus, we observed scleral melt on the graft recipient border. These complications propelled us to look for a technique which would enable harvesting a graft big enough to cover all the impairments which were to be removed, might give better visual outcomes due to positioning the sutures not in the visual axis, and would graft limbal stem cells. That is why we decided to perform sclerokeratoplasty on 360 degrees. We believe that the final effect of this procedure may corroborate the rationale for our treatment paradigm.

Systemic immunosuppression is the main disadvantage of this method. There are no consistent details concerning immunosuppressive treatment, dosage, and its duration. From many different schemes, we concluded that at least two systemic immunosuppressive agents are necessary to prevent sclerocorneal graft from rejection [16-21]. In our case, we followed the orders of the specialist in organ transplantations from our institute based on recommendations of the European Society of Organ Transplantation (ESOT) [22].
Although sclerokeratoplasty is not a standard procedure for the treatment of corneal perforation, it may be effective in some cases of the perforation of an anaesthetic cornea, especially when the standard penetrating keratoplasty is of poor prognosis or impossible to be performed due to the anatomy of the lesions. Further investigation is needed to confirm the effectiveness and safety of this method.

This paper was accepted as a scientific poster for the European Society of Ophthalmology Congress (SOE), Copenhagen, Denmark, 8-11 June 2013, and was presented at the 5th International Symposium "Advances in diagnosis and treatment of corneal diseases," Wisla, Poland, 7-9 March 2013.

\section{Conflict of Interests}

The authors declare that there is no conflict of interests regarding the publication of this paper.

\section{References}

[1] V. Darrouzet, J. Martel, V. Enée, J. P. Bébéar, and J. Guérin, "Vestibular Schwannoma surgery outcomes: our multidisciplinary experience in 400 cases over 17 years," Laryngoscope, vol. 114, no. 4, pp. 681-688, 2004.

[2] V. Puangsricharern and S. C. G. Tseng, "Cytologic evidence of corneal diseases with limbal stem cell deficiency," Ophthalmology, vol. 102, no. 10, pp. 1476-1485, 1995.

[3] S. Sigelman and J. S. Friedenwald, "Mitotic and wound-healing activities of the corneal epithelium: effect of sensory denervation," AMA Archives of Ophthalmology, vol. 52, no. 1, pp. 46-57, 1954.

[4] T. W. Mittag, J. S. Mindel, and J. P. Green, “Trophic functions of the neuron. V. Familial dysautonomia. Choline acetyltransferase in familial dysautonomia," Annals of the New York Academy of Sciences, vol. 228, pp. 301-306, 1974.

[5] J. B. Jonas, R. M. Rank, and W. M. Budde, "Tectonic sclerokeratoplasty and tectonic penetrating keratoplasty as treatment for perforated or predescemetal corneal ulcers," American Journal of Ophthalmology, vol. 132, no. 1, pp. 14-18, 2001.

[6] A. A. Bialasiewicz and G. O. H. Naumann, "Tectonic keratoplasty to treat perforated corneal ulcer in Sjogren's syndrome," Klinische Monatsblatter fur Augenheilkunde, vol. 193, no. 6, pp. 554-564, 1988.

[7] A. Panda, "Lamellolamellar sclerokeratoplasty. Where do we stand today?" Eye, vol. 13, part 2, pp. 221-225, 1999.

[8] M. Cobo, J. R. Ortiz, and S. G. Safran, "Sclerokeratoplasty with maintenance of the angle," American Journal of Ophthalmology, vol. 113, no. 5, pp. 533-537, 1992.

[9] D. J. Coster, "An alternative approach to corneoscleral repair," British Journal of Ophthalmology, vol. 77, no. 6, p. 325, 1993.

[10] A. Lambiase, M. Sacchetti, and S. Bonini, "Nerve growth factor therapy for corneal disease," Current Opinion in Ophthalmology, vol. 23, no. 4, pp. 296-302, 2012.

[11] S. Bonini, A. Lambiase, P. Rama, G. Caprioglio, and L. Aloe, "Topical treatment with nerve growth factor for neurotrophic keratitis," Ophthalmology, vol. 107, no. 7, pp. 1347-1351, 2000.

[12] A. Lambiase, P. Rama, S. Bonini, G. Caprioglio, and L. Aloe, "Topical treatment with nerve growth factor for corneal neurotrophic ulcers," New England Journal of Medicine, vol. 338, no. 17, pp. 1174-1180, 1998. 
[13] C. Khammari Chebbi, K. Kichenin, N. Amar et al., "Pilot study of a new matrix therapy agent (RGTA OTR4120) in treatmentresistant corneal ulcers and corneal dystrophy," Journal Francais d'Ophtalmologie, vol. 31, no. 5, pp. 465-471, 2008.

[14] V. Jhanji, A. L. Young, J. S. Mehta, N. Sharma, T. Agarwal, and R. B. Vajpayee, "Management of corneal perforation," Survey of Ophthalmology, vol. 56, no. 6, pp. 522-538, 2011.

[15] N. Sharma, R. Sachdev, V. Jhanji, J. S. Titiyal, and R. B. Vajpayee, "Therapeutic keratoplasty for microbial keratitis," Current Opinion in Ophthalmology, vol. 21, no. 4, pp. 293-300, 2010.

[16] T. Reinhard, R. Sundmacher, and P. Heering, "Systemic ciclosporin A in high-risk keratoplasties," Graefe's Archive for Clinical and Experimental Ophthalmology, vol. 234, supplement 1, pp. S115-S121, 1996.

[17] J. C. Hill, "Immunosuppression in corneal transplantation," Eye, vol. 9, no. 2, pp. 247-253, 1995.

[18] J. C. Hill, "Systemic cyclosporine in high-risk keratoplasty: short-versus long-term therapy," Ophthalmology, vol. 101, no. 1, pp. 128-133, 1994.

[19] J. Y. Niederkorn, "Corneal transplantation and immune privilege," International Reviews of Immunology, vol. 32, no. 1, pp. 57-67, 2013.

[20] P. Nguyen, F. Barte, S. Shinada, and S. C. Yiu, "Management of corneal graft rejection-a case series report and review of the literature," Journal of Clinical \& Experimental Ophthalmology, vol. 1, article 103, 2010.

[21] J. B. Randleman and R. D. Stulting, "Prevention and treatment of corneal graft rejection: current practice patterns (2004)," Cornea, vol. 25, no. 3, pp. 286-290, 2006.

[22] L. Paczek, B. Foroncewicz, and K. Mucha, "Transplantologia praktyczna," in Postepy W Transplantologii, vol. 4, pp. 195-196, Wydawnictwo Naukowe PWN, 2013. 


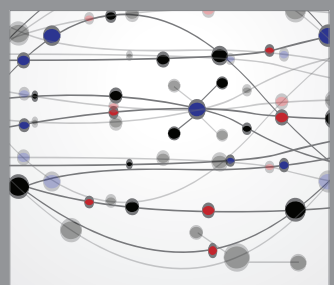

The Scientific World Journal
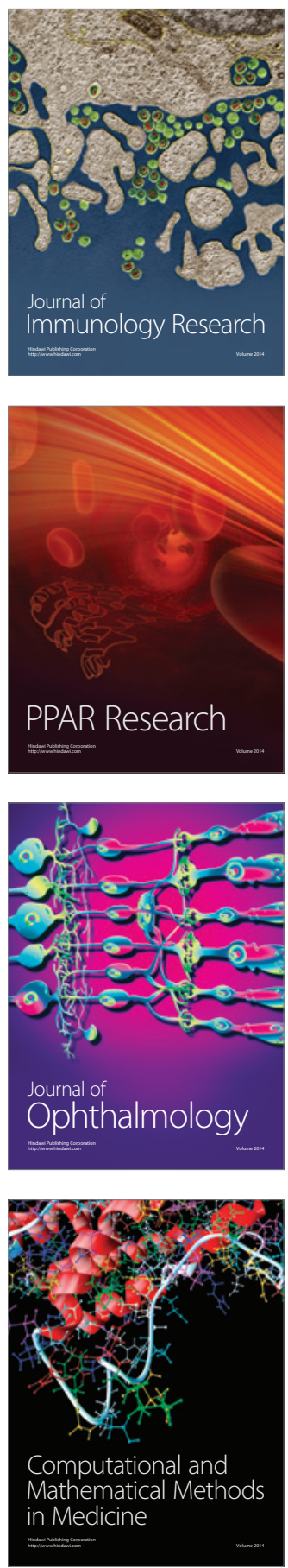

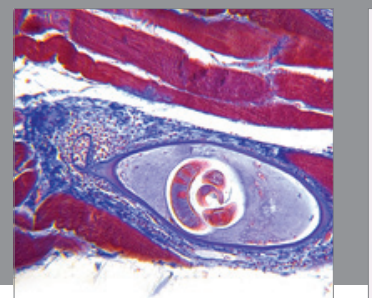

Gastroenterology

Research and Practice
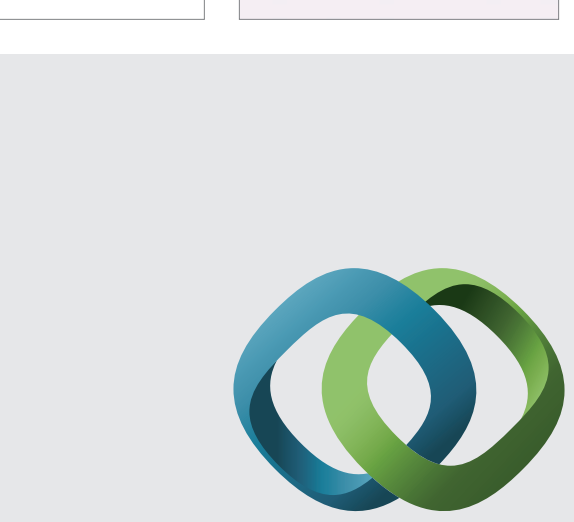

\section{Hindawi}

Submit your manuscripts at

http://www.hindawi.com
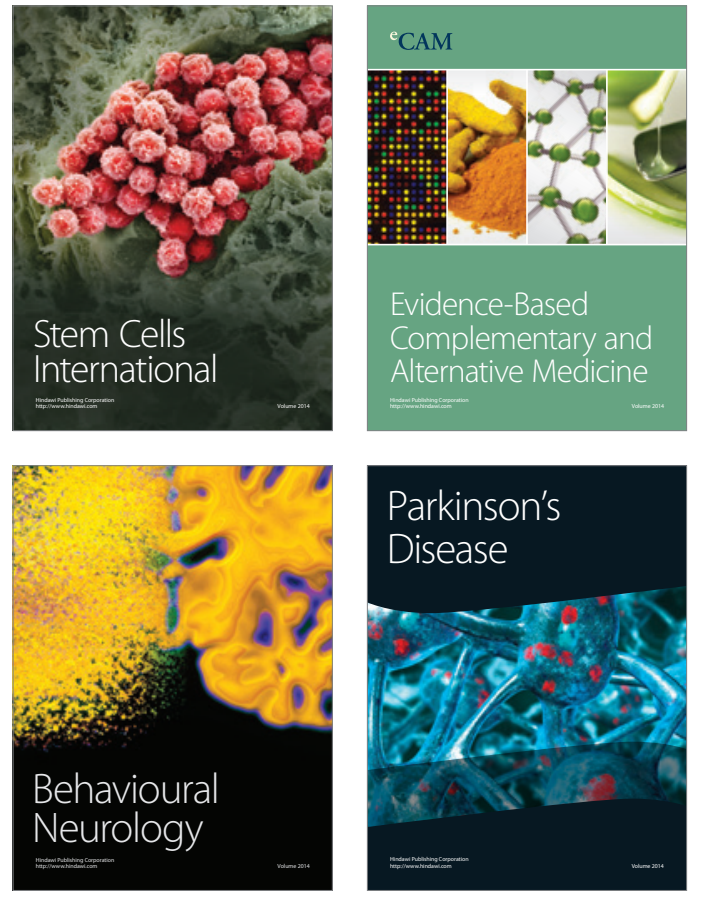
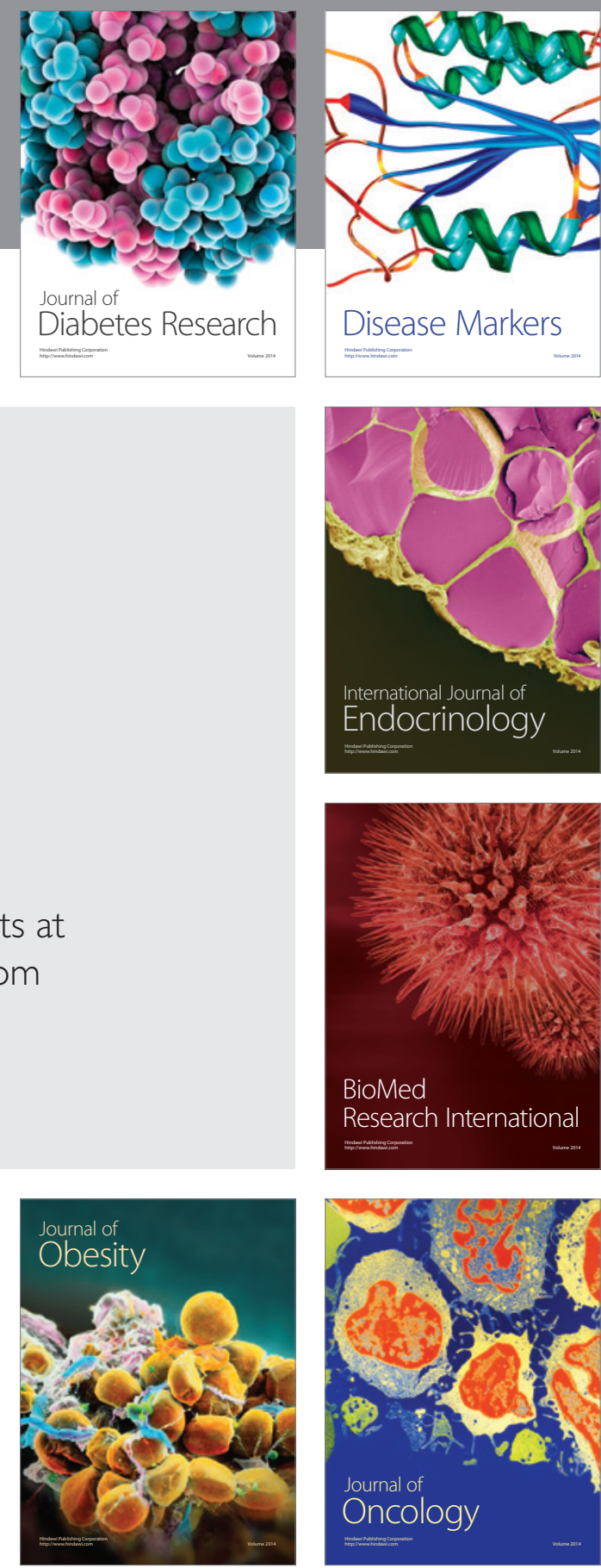

Disease Markers
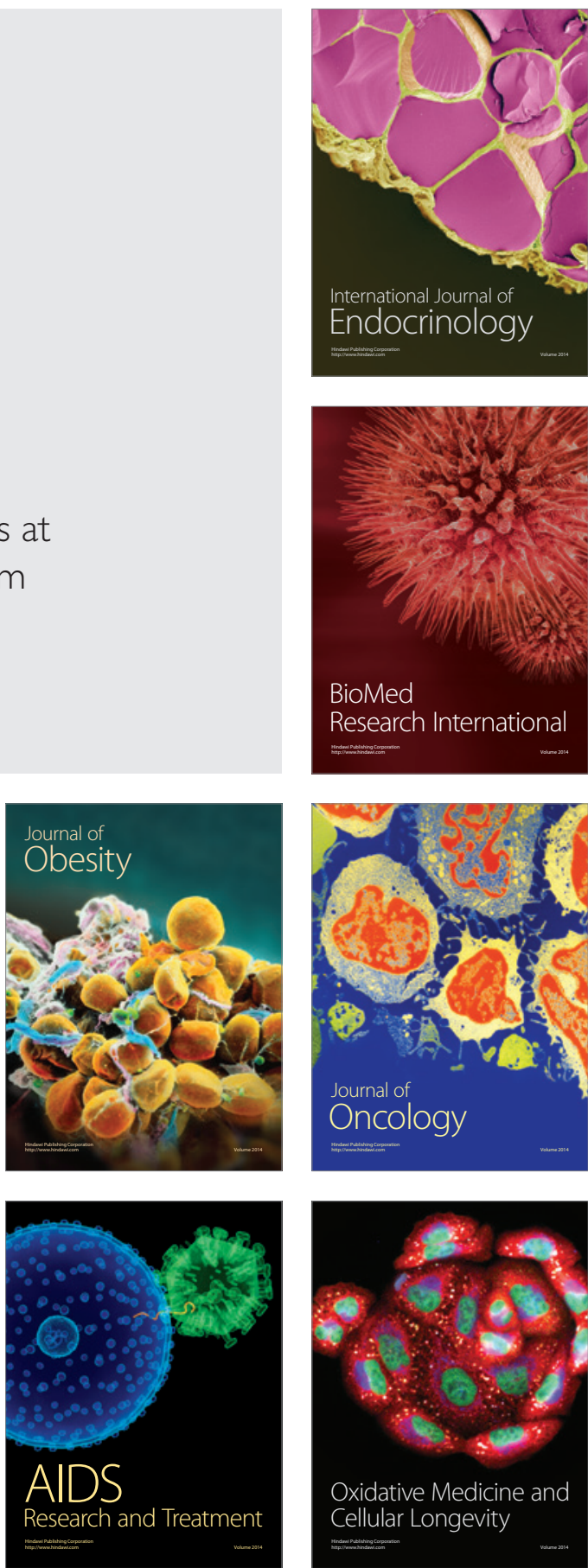